\title{
Enhancing Cognitive Theory of Multimedia Leaning through 3D Animation
}

\author{
Zeeshan Bhatti ${ }^{1}$, Abdul Waheed Mahesar ${ }^{1}$, Ghullam Asghar Bhutto ${ }^{1}$, Fida \\ Hussain Chandiio ${ }^{2}$
}

\begin{abstract}
Cognitive theory of Multimedia learning has been a widely used principle in education. However, with current technological advancements and usage, the teaching and learning trend of children have also changed with more dependability towards technology. This research work explores and implement the use of 3D Animation as a tool for multimedia learning based on cognitive theory. This news dimension in cognitive learning will foster the latest multimedia tools and application driven through 3D Animation, Virtual Reality and Augmented Reality. The three principles, that facilitate cognitive theory of multimedia learning using animation, addressed in this research are temporal contiguity principle (screening matching narration with animation simultaneously rather than successively), personalization principle (screening text or dialogue in casual form rather than formal style) and finally the multimedia principle (screen animation and audio narration together instead of just narration). The result of this new model would yield a new technique of educating the young children through 3D animation and virtual reality. The adaptation of cognitive theory through 3D animation as a source of multimedia learning with various key principles produces a reliable paradigm for educational enhancement.
\end{abstract}

Keywords: Multimedia Learning, Animation, Cognitive Theory

\section{Introduction}

People tend to learn better and accurate from combination of words and pictures, rather than just from words alone [1]. A famous slogan used to highlight the power of pictures states "A Picture is worth a Thousand Words" [2]. This slogan alone emphasis that through a single picture, thousand words worth of information can easily be conveyed to the learner. Multimedia Learning deals with teaching instructions given with aid of Graphics/images along with verbal words. Multimedia instruction deal with presenting the teaching materials using both Words or Text and Pictures or Graphics, with prime goal of promoting student learning [3]

The basic principle behind multimedia learning is that the students tend to understand and learn more effectively, the topic being taught is presented in words and pictures combined as compared to only words. Multimedia based communications can be grounded on following [1], [3].

- Delivery Media; this involves having a projector screen with multimedia speaker system.

- Presentation Mode; this involves the way in which teaching is communicated, for example words and illustrations or pictures.

- Sensory Modalities; the third type involves human senses that are able to capture the information such as auditory senses and visual senses.

Based on these modes, the Instructional multimedia based information and text can be centered around technology-centered approach that specifically focus on the usability and implications of the advance technological tools and trends. Whereas, the

${ }^{1}$ Institute of Information and Communication Technology, University of Sindh Jamshoro

${ }^{2}$ Institute of Mathematics and Computer Science, University of Sindh Jamshoro

Corresponding email: zeeshan.bhatti@ usindh.edu.pk 
second approach can be directed towards the learner-centered that is primarily targeted towards the human cognitive system and its natural behaviors [3]. Various studies show that every student can gain knowledge and understanding from a multimedia based simulated environment. They can also apply that knowledge and information in some real world scenarios.

\section{Similar Work}

There has been several research work in the field of Instructional multimedia learning. A computer based brake mechanism has been effectively described using animated illustrations of the entire process as shown in Figure 1. Whereas, an interactive multimedia (IMM) program has been developed that demonstrates young children about the rules and do's and don'ts of safe pedestrian skills [9], shown in figure 2. Similarly, in Figure 3, Virtual reality and multimedia technology tools are again used to train the children in safe street-crossing skills [10].

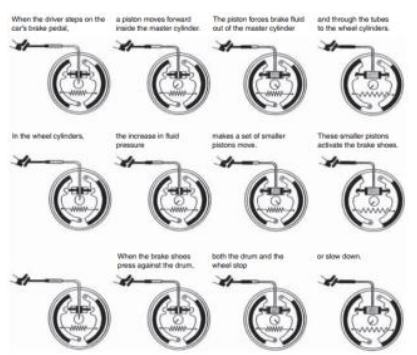

Figure 1: Frames from the narrated animation for the computer-based brakes lesson (source [3]).

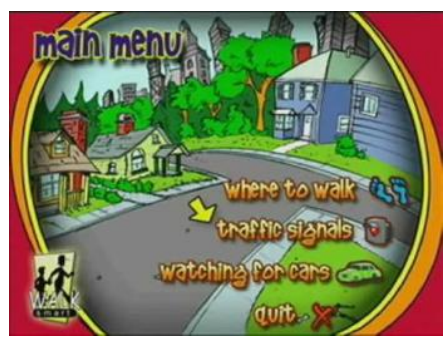

Figure 2: An interactive multimedia (IMM) platform that educates young children about the safe pedestrian skills (source [9]).

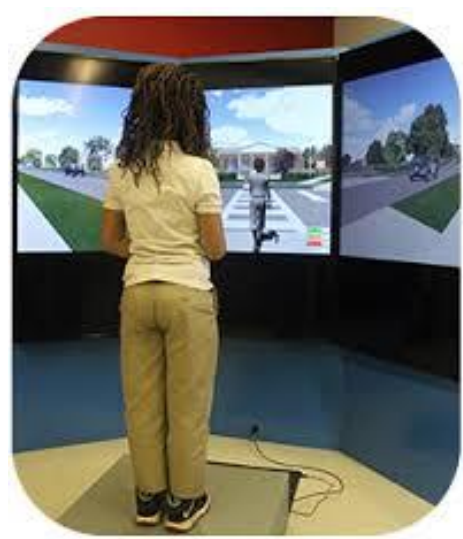

Figure 3: Using virtual reality to train children in safe street-crossing skills [10]

Whereas, another pictorial animation is created to develop a multimedia based teaching lesson on how a tire pump Works as illustrated in figure 4, [8] [11]. The role and importance of education and respecting the tools of education are discussed in [13], as shown in figure 5.

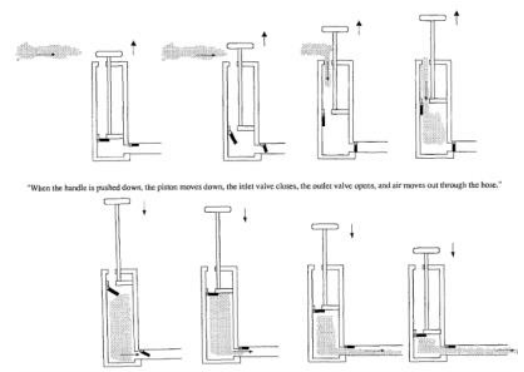

Figure 4: Selected animation frames and corresponding narration from a multimedia lesson on how a tire pump Works [8] [11].

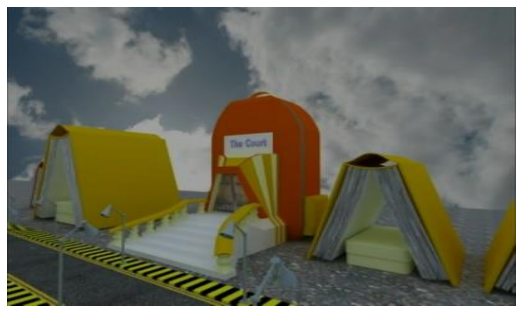

Figure 5: Be-Educated: Multimedia Learning through 3D Animation [13] 
The simple process of six segments of static illustrations of the flushing toilet tank is again taught through illustrations as shown in figure 6, [12]. Whereas, a Research Framework was purposed for FIQIR Road Safety system, to teach children about road safety using multimedia tools as shown in figure 7, [14].
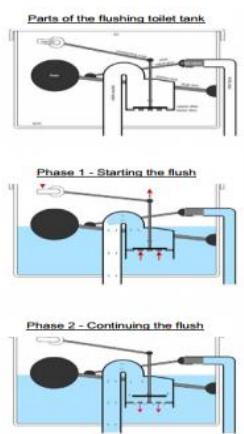
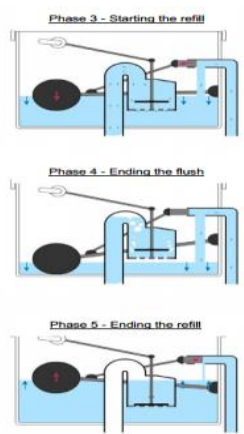

Figure 6: Six segments of static illustrations of the flushing toilet tank [12]

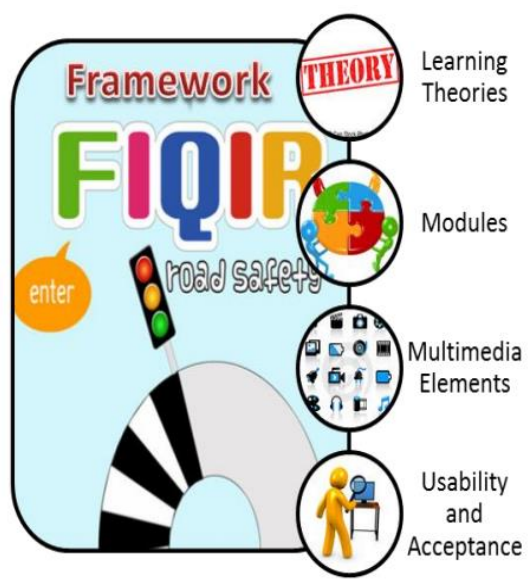

Figure 7. Research Framework for FIQIR Road Safety [14]

Similarly, Application of Interactive Multimedia Tools in Teaching Mathematics was discussed in [15] as illustrated in Figure 8 .

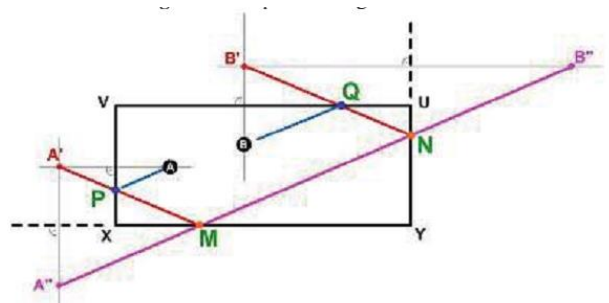

Figure 8: Lessons from Geometry [15]

\section{Multimedia Learning}

Multimedia learning is generally viewed as having three basic principle objectives. First being Response strengthening, under which the responses of the learners are tested and made stronger through drill-and-practice system. Second principle is Information Acquisition, where multimedia technology and tools are used to transfer information and text data to the learner. Finally, the third principle is Knowledge Construction, through which an understanding and logical sense is developed about the subject matter in order to increase the retention of given knowledge.

\subsection{Cognitive Theory of Multimedia Learning}

The cognitive theory of multimedia learning (CTML) is centered on three cognitive science principles of learning [1][4][5]. First Principle, for processing of information two separate - Audio and Visual data, channels are to be used. Second Principle says that the channel capacity will always be limited, exposing the fact that there will be only a partial and restricted amount of information that can be actively processed at any single given time. Third Principle states that the learning is an active process concerning and dealing with filtering, selecting, organizing, and integrating information. These principles and their relational working are illustrated in 
Figure

Cognitive Theory of Multimedia Learning

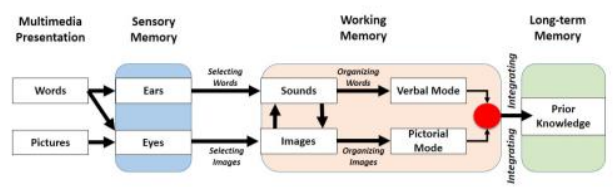

Figure 9: Illustrates the basics of cognitive theory of multimedia learning (Source: [1]).

\section{Research Question}

Q1. HOW to Improve Students Learning?

The central question of research is that: How can we design multimedia instructions that improves students understanding of the presented material? The two qualitative variables to be considered are learning and retention rate. How learning can be achieved effectively, that would yield a better and higher retention rate.

\subsection{Animation to the rescue}

Through this project, an approach to combine the cognitive multimedia learning principle with Animation based Learning techniques is designed. Generally, multimedia learning involves, images and video along with text, still 3D animation techniques are employed to attain a level of sophistication through which a strong message and lesson on education can be portrayed.

It has been discussed and proven by many researchers that animation can encourage and enhance the ability of the learner and viewer to understand and gain the message. Especially, when it has been used within the principles of cognitive theory of multimedia learning [1][4][5][6].

\section{a. What is Animation?}

Computer Animation refers to sequence of frames or images in which the subject/object is changing its position or orientation with respect to time in each subsequent frame in succession, that yield the perception of motion [7]. Animation can promote learner understanding when used in ways that are
9. consistent with the cognitive theory of multimedia learning. [6]

\subsection{Animation as an Aid to cognitive Multimedia Learning}

In order to address the research question discussed above, we purpose a modified version of Cognitive theory that uses a new dimension of Animation and Regional language, to be incorporated in multimedia learning as highlighted in figure 10. Through these two new parameters, i.e. Regional Language based instructional media and use of 3D Animation to describe the complex scientific phenomena's, the current Hypothesis is that it would significantly increase the learner's ability to understand and grasp the knowledge. While the same would result in increasing the retention rate of the learner. In our Model of Animation based Cognitive Theory of Multimedia Learning (ACTML), we Introduce animation as the third channel of instructional multimedia learning and propose a new model for ACTML [16].

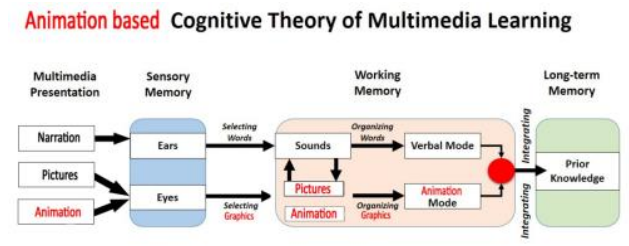

Figure 10: Purposed and Modified version of Cognitive Theory of Multimedia Learning.

\section{Principles of using Animation with cognitive Multimedia Learning}

In order to use animation with cognitive theory, we have devised the following three principles in conjunction with multimedia learning

A) Animation principle (screen animation and audio narration together instead of just narration).

B) Temporal contiguity principle (screening matching narration with 
animation simultaneously rather than successively)

C) Personalization principle (screening text or dialogs in casual form rather than formal style).

\subsection{Animation principle}

The first principle we propose and emphasis on is that the students are expected to understand and remember the taught topic easily and with profound accuracy, if that topic is taught with specially created 3D animation principles, along with text and voice based narrations. This principle is based on simple rationale fact that the students are able to respond much better towards moving illustrations and 3D animations along with textual captions and voice narrations.

\subsection{Temporal contiguity principle}

The second principle that we have used is derived from the basic rule that students understand and learn the topic more profoundly and easily when the multimedia instructions containing test/words/narration is presented synchronously with the animation. This principle simply relies on the theoretical validation that each student is better able to focus and follow when the narrations, textual caption and animation are all synchronized together seamlessly [6].

\subsection{Personalization principle}

The third principle we adopted was, that the students understand and learn the topic more profoundly and easily from animated and narration specially when the voice based recitation is in general casual conversational form rather than based on official technical wording with formal style.

\section{Conclusion}

Multimedia learning is a technique that enhances and facilitates the learner's internal information system that comprises visual and verbal channels of processing information. This system requires a cognitive processing at each level for ability to learn and gain knowledge from taught topic, effectively. In order to enhance this ability, we introduced a third channel of Animation, into the Cognitive theory of multimedia learning. Animation is a very powerful means and mode of communication, whereby the knowledge of deep and complicated phenomenon can be easily taught to students. The use of animation in multimedia learning is structured on three codes of cognitive theory, these principles are Multimedia principle, temporal contiguity principle and personalization principle, which will produce new dimensions of multimedia learning.

\section{ACKNOWLEDGMENT}

This research work was carried out in Multimedia Animation and Graphics (MAGic) Research Group at Institute of Information and Communication Technology, University of Sindh, Jamshoro.

\section{REFERENCES}

[1] Mayer, R. E. (2014). Cognitive theory of multimedia learning. The Cambridge handbook of multimedia learning, 43.

[2] Pinsky, L. E., \& Wipf, J. E. (2000). A picture is worth a thousand words. Journal of general internal medicine, 15(11), 805-810.

[3] Mayer, R. E. (2001)."Multimedia Learning" Chapter 1, Cambridge University Press, 2001.

[4] Mayer, R. E. (2005). "Cambridge Handbook of Multimedia Learning", Chapter 1 and Chapter 2. Cambridge University Press, 2005.

[5] Moreno, R., \& Mayer, R. E. (1999). Cognitive principles of multimedia learning: The role of modality and contiguity. Journal of educational psychology, 91(2), 358.

[6] Mayer, R. E., \& Moreno, R. (2002). Animation as an aid to multimedia learning. Educational psychology review, 14(1), 87-99.

[7] Thalmann, N. M., \& Thalmann, D. (1990). Computer Animation. In Computer Animation (pp. 13-17). Springer Japan.

[8] Mayer, R. E. (1997). Multimedia learning: Are we asking the right questions?. Educational psychologist, 32(1), 1-19.

[9] Glang, A., Noell, J., Ary, D., \& Swartz, L. (2005). Using interactive multimedia to teach pedestrian safety: An exploratory study. American journal of health behavior, 29(5), 435-442. 
10] Schwebel, D. C., \& McClure, L. A. (2010). Using virtual reality to train children in safe streetcrossing skills. Injury prevention, 16(1), e1-e1. [11] Mayer, R. E., \& Anderson, R. B. (1992). The instructive animation: Helping students build connections between words and pictures in multimedia learning. Journal of educational Psychology, 84(4), 444.

[12] Paik, E. S., \& Schraw, G. (2013). Learning with animation and illusions of understanding. Journal of Educational Psychology, 105(2), 278.

[13] Abro, A., Bhatti, Z., Gillal, A.R., Mahesar, A.W., Karbasi, M., (2016), Be-Educated: Multimedia Learning through 3D Animation. Pakistan Journal of Engineering and Applied Sciences (submitted)

[14] Rawi, N. A., Mamat, A. R., Deris, M. S. M., Amin, M. M., \& Rahim, N. (2015). A Novel
Multimedia Interactive Application to Support Road Safety Education among Primary School Children in Malaysia. Jurnal Teknologi, 77(19).

[15] Milovanovic, M., Obradovic, J., \& Milajic, A. (2013). Application of Interactive Multimedia Tools in Teaching Mathematics-Examples of Lessons from Geometry. TOJET: The Turkish Online Journal of Educational Technology, 12(1).

[16] Bhatti, Zeeshan and Waqas, Ahmed and Mahesar, Abdul Waheed and Chandio, Fida and Bhutto, Ghullam Asghar, (2017) "Use of Multimedia, Temporal Contiguity \& Personalization principles in Cognitive Multimedia learning through 3D Animation", in proceedings of International Conference on Computing and Mathematical Sciences, at Sukkur IBA, 25-26 February, 2017. 